\title{
Evaluation of Antifungal, Hemolytic and Cytotoxic Potential of Ethyl Acetate Extract of a New Marine Streptomyces sp. AIAH-10
}

\author{
Md. Anwarul Haque ${ }^{1}$, Ashish Kumar Sarker', Md. Ajijur Rahman², \\ Md. Aktar Uzzaman Chouduri ${ }^{2}$ and Md. Anwar UI Islam² \\ ${ }^{1}$ Department of Pharmacy, Pabna University of Science and Technology, Pabna-6600, Bangladesh \\ ${ }^{2}$ Department of Pharmacy, University of Rajshahi, Rajshahi-6205, Bangladesh
}

Received: April 24, 2015; Accepted: December 02, 2015; Published (Web): February 17, 2016

\begin{abstract}
To face newly generated diseases, search for new, safe and effective bioactive molecules is highly warranted. The marine microbial flora may be a potential source of such molecules. The present study was designed to isolate marine microorganisms (AIAH-1 to AIAH-29) from the soil of mangrove forest Sundarbans, Bangladesh by serial dilution method using isolation media. Among them, AIAH-10 was selected for further study due to its promising antibacterial activity (done by streak plate and plug technique method) against a series of pathogenic bacteria. On the basis of morphological, cultural and biochemical analysis, the strain AIAH-10 belongs to Streptomyces sp. Secondary metabolites of the strain was obtained by small scale fermentation process. Antifungal activity of the extracts was performed by disc diffusion method. The crude ethyl acetate extract $(50 \mu \mathrm{g} / \mathrm{disc})$ showed significant antifungal activity against Aspergillus niger, Candida albicans and Saccharromyces cerevaceae (14, 12 and $10 \mathrm{~mm}$ zone of inhibition respectively). No hemolytic activity was found of the extracts towards the human erythrocytes. During cytotoxic study against brine shrimp nauplii (Artemia salina), a dose dependent mortality rate was observed. A $100 \%$ larva mortality rate was recorded in $40 \mu \mathrm{g} / \mathrm{ml}$ and more where as $\mathrm{LC}_{50}$ was found to be $6.61 \mu \mathrm{g} / \mathrm{ml}$.
\end{abstract}

Key words: Marine streptomyces, cross streak method, fermentation, antibacterial activity, hemolytic activity

\section{Introduction}

Marine habitat has been proven as an outstanding and fascinating resource for innovating new and potent biomolecules producing microorganisms that has not been properly screened (Uzzal et al., 2015). It is reported that not more than $1 \%$ of the bioactive compounds from marine ecosystem have been isolated (Haque et al., 2015). Exploration of unscreened marine locality has led to the discovery of hundreds of biologically active compounds. Compared with terrestrial organisms, the secondary metabolites produced by marine organisms have broader bioactivities, more novel \& unique structures owing to the complex living circumstance and diversity of species (Carte, 1996 and Schwartsmann et al., 2001).
Moreover, marine derived antibiotics are more efficient at fighting against pathogens over terrestrial bacteria and have not developed any resistant against them (Jensen et al., 2005). A number of marine organisms including actinomycetes, which live in marine environment, are inadequately understood and only few reports are available pertaining to marine oriented microorganisms (Siva, 2011). The actinomycetes are an important part of the microbial community in the soil environment, responsible for degradation and recycling of natural biopolymers, such as cellulose, lignin and chitin (Semedo et al., 2001). The species belonging to the genus Streptomyces constitute 50\% of the total population of soil actinomycetes and are well known for producing a variety of bioactive secondary

Correspondence to: Md. Anwar Ul Islam, Phone: +88-0721-711110; Fax: +88-0721-750064;

E-mail: profanwarulislam@yahoo.com 
metabolites including antibiotics, immunomodulators, anticancer \& antiviral drugs, herbicides, and insecticides (Rahman et al., 2010). Although thousands of antibiotics have been isolated from Streptomyces, these represent only a small fraction of the repertoire of bioactive compounds produced (Berdy, 1995 and Watve et al., 2011). So, still there is a chance of discovery of new Streptomyces species producing novel compounds from this genus. From the soil of mangrove forest Sundarbans, Bangladesh, previously we discovered several new species of actinomycetes (e.g., Smithella propionica, Syntrophus aciditrophicus) as well as some novel bioactive compounds having significant biological activities (Sarker et al., 2015). Recently, we reported the isolation and characterization of a marine Streptomyces sp. and the initial screening showed interesting antibacterial and insecticidal activities (Haque et al., 2014).

In this study, we report the antifungal, hemolytic and brine shrimp lethality bioassay of the crude extract obtained from the solid fermentation media of Streptomyces sp. AIAH-10.

\section{Materials and Methods}

Collection of marine soil samples:Marine soil samples were collected from the marine sediments and different locations of mangrove forest (Sundarbans), like Kochikhali, Jamtoplapoint, Tigerpoint, Dublarchor, Koramjol of Bangladesh, from the layers beneath the upper surface to the $1.5 \mathrm{~cm}$ depth during March 2012. Samples were collected in plastic bag with proper labeling. Sixteen soil samples were collected and allowed to dry in hot air oven at $121{ }^{\circ} \mathrm{C}$ for about 3 hours to remove spores from the vegetative cells (Karthik et al., 2010) and stored at $4{ }^{\circ} \mathrm{C}$ till further processing.

Isolation of soil actinomycetes: Actinomycetes isolation from marine soil sediments was performed by serial dilution and spread plate method. One gram of previously processing soil sample was serially diluted in sterilized distilled water to get a concentration ranging from $10^{-1}$ to $10^{-6}$. A volume of $80 \mu \mathrm{l}$ of each dilution was transferred aseptically to isolation medium (casein starch glucose media) which was supplemented with nystatin $(25 \mu \mathrm{g} / \mathrm{ml})$ to remove the growth of fungi.
The sample was spread uniformly to the sterile plate by rotating it clockwise and anticlockwise direction. The plates were incubated at room temperature for 7 days (Sivakumar et al., 2005). The actinomycetes strains were picked up as they are dusky and powdery in nature as well as earthy odor. The isolated strains were further subcultured on the respective media in order to obtain pure culture. Pure isolates were maintained at $4^{\circ} \mathrm{C}$ in refrigerator for further studies.

Primary screening of isolates for antibacterial activity (cross streak method): Primary screening of the isolated actinomycetes was performed by cross streak method on modified nutrient agar (MNA) plates (Santina et al., 2009). The actinomycetes isolates were inoculated in straight line on MNA plates and incubated for 7 days. Pathogenic bacterial strains were cross streak on the same plate in perpendicular manner. The plates were incubated at $37{ }^{\circ} \mathrm{C}$ for 24 hours and examined for the length of inhibition.

Characterization of potential strain: The isolated strain AIAH-10 having potent antibacterial activity was subjected for morphological, cultural and biochemical study to identify the strain.

Fermentation and isolation of secondary metabolites: The antagonistic actinomycetes isolate's suspensions were prepared by suspending a loopful of pure colony in $2 \mathrm{ml}$ sterile normal saline, vortexed to homogenize and stored at $4{ }^{\circ} \mathrm{C}$ until ready for use. This suspension was used as Streptomyces inoculants in all cultivations. Fermentation for production of bioactive metabolites was done as described by Umasankar 2010 with modification. $100 \mu \mathrm{l}$ isolate suspension was inoculated in $100 \mathrm{ml}$ of modified nutrient (MN) broth in Erlenmeyer flasks. Flasks were lodged on the flask shaker at a speed of $120 \mathrm{rpm}$ at room temperature for 8 days. After fermentation, the medium was harvested and centrifuged to remove growth and debris. The bioactive compounds were recovered from the harvested medium by solvent extraction method. The culture supernatant was extracted twice with equal volumes of ethyl acetate $(1: 1 \mathrm{v} / \mathrm{v})$, shaken vigorously for 1 hour in a solvent extraction funnel, vaporized to dryness in a rotary evaporator at $50{ }^{\circ} \mathrm{C}$ and dried in lyophilizer. 
Collection of test species: Three pure fungal strains Aspergillus niger, Saccharromyces cerevaceae and Candida albicans were collected from ICDDR'B. The eggs of the brine shrimp, Artemia salina, were collected from an aquarium shop, Dhaka, Bangladesh.

Antifungal Activity: Antifungal activity was done by disc diffusion method (Iqbal et al., 2004). The fungi cultures were maintained in Sabouraud's dextrose broth. From this $100 \mu \mathrm{l}$ suspension of each culture was uniformly distributed on Sabouraud's dextrose agar (SDA) plates. Sterile filter paper discs containing crude extracts $(50 \mu \mathrm{g} / \mathrm{disc})$ and standard Nystatin discs (30 $\mu \mathrm{g} / \mathrm{disc}$ ) were placed on the surface of Sabouraud's dextrose agar (SDA) plates. The plates were prepared at $4{ }^{\circ} \mathrm{C}$ for 4 hour to diffuse the extracts and nystatin to the surrounding media. Then, the inoculated plates were incubated at $27^{\circ} \mathrm{C}$ for 48 hour. At the end of incubation period, the zones of inhibition were measured.

Hemolytic activity: Hemolytic activity was carried out by using blood agar plate method. The ethyl acetate extract was used to detect the hemolytic activity. The blood agar plates were prepared by adding human blood (5\%) to blood agar base. Wells were punched on the blood agar surface by using a gel borer. The ethyl acetate extracts were prepared $1000 \mu \mathrm{g} / \mathrm{ml}$ concentration and a volume of $100 \mu \mathrm{l}$ was transferred aseptically into the well. Then plates were incubated at $37^{\circ} \mathrm{C}$ for $12 \mathrm{hrs}$. The plates were then examined for the zone of hemolysis (Sathish et al., 2011).

Cytotoxic profile: Brine shrimp lethality bioassay (Jaki et al., 1999 and Mayer et al., 1982] is a recent development in the assay procedure of bioactive compounds which indicates cytotoxicity as well as a wide range of pharmacological activities (e.g. anticancer, antiviral, insecticidal, pesticidal, AIDS, etc) of the compounds. In brief, the eggs of brine shrimp, Artemia salina were hatched in seawater. Ten mature larvae (nauplii) were kept in glass vials containing 10 $\mathrm{ml}$ of seawater. The extracts dissolved in DMSO (10 $\mathrm{mg} / \mathrm{ml}$ ) were applied to the nauplii in each vial. However, not more than $50 \mu \mathrm{l}$ of DMSO was added to the vials containing the shrimps. For each concentration, vials containing the same volume of DMSO plus seawater and shrimps were used as control. After $24 \mathrm{~h}$, the vials were observed for mortality with the help of magnified glass. The number of survived nauplii in each vial was counted and from this data, the percentage of lethality of the brine shrimp nauplii was calculated. The findings were presented graphically by plotting concentration versus percentage of mortality of nauplii from which $\mathrm{LC}_{50}$ was determined by extrapolation.

\section{Results}

Total 29 actinomycetes were isolated from different marine soil samples of Sundarbans (Bangladesh) surroundings. Colonies of actinomycetes in isolation plate are shown in figure1. These were designed as AIAH-1 to AIAH-29 (Table 1).

Table 1. Collection site, depth and number of actinomycetes colonies per gram of soil.

\begin{tabular}{llcc}
\hline $\begin{array}{l}\text { Collection } \\
\text { site }\end{array}$ & $\begin{array}{l}\text { Dept of } \\
\text { sample }\end{array}$ & $\begin{array}{c}\text { Number of colony/ } \\
\text { gm of soil }\end{array}$ & Isolate strains \\
\hline Dublarchor & 8 inches & $1.2 \times 10^{4}$ & $\begin{array}{c}\text { AIAH-1 to } \\
\text { AIAH-12 }\end{array}$ \\
Kochikhali & 6 inches & $0.7 \times 10^{4}$ & AIAH-13 to \\
& & $1.0 \times 10^{4}$ & AIAH-19 \\
Koromjol, & 1 feet & & AIAH-20 to 29 \\
\hline
\end{tabular}

Among the 29 isolates, $73.53 \%$ exhibited antimicrobial activity during primary screening (Table 2). The isolate AIAH-10 showing promising broad spectrum activity against different pathogenic organisms (Figure 2) was selected for further study. The potential strain AIAH-10 was identified by morphological, cultural and biochemical study. The complete data was reported in table 3 and 4 . Findings of this study suggested that the strain was belonged to Streptomyces sp.

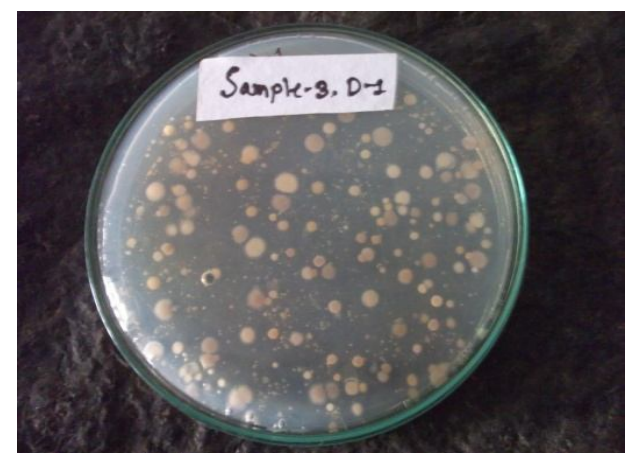

Figure 1. Colonies of actinomycetes appeared on the dilution plates using the marine soil sample. 
Table 2. Diameter of length of inhibition (in $\mathrm{mm}$ ) of the isolates against pathogenic bacteria.

\begin{tabular}{lccccccc}
\hline ID number & $\begin{array}{l}\text { Streptococcus } \\
\text { agalactiae }\end{array}$ & $\begin{array}{l}\text { Bacillus } \\
\text { cereus }\end{array}$ & $\begin{array}{l}\text { Pseudomonas } \\
\text { aeruginosa }\end{array}$ & $\begin{array}{l}\text { Escherichia } \\
\text { coli }\end{array}$ & $\begin{array}{l}\text { Shigella } \\
\text { dysenteriae }\end{array}$ & $\begin{array}{l}\text { Shigella } \\
\text { sonnei }\end{array}$ & Agrobacterium \\
\hline AIAH-01 & $15 \pm 0.12$ & $22 \pm 0.13$ & $16 \pm 0.17$ & $20 \pm 0.27$ & $20 \pm 0.32$ & $30 \pm 0.16$ & $21 \pm 0.14$ \\
AIAH-02 & $02 \pm 0.31$ & $05 \pm 0.26$ & $04 \pm 0.14$ & $02 \pm 0.16$ & - & - & $04 \pm 0.37$ \\
AIAH-05 & $21 \pm 0.34$ & $28 \pm 0.21$ & $19 \pm 0.17$ & $27 \pm 0.34$ & $30 \pm 0.11$ & $22 \pm 0.23$ & $20 \pm 0.41$ \\
AIAH-06 & $10 \pm 0.24$ & $12 \pm 0.41$ & $07 \pm 0.23$ & $09 \pm 0.34$ & $15 \pm 0.27$ & - & $12 \pm 0.24$ \\
AIAH-07 & - & - & - & - & - & - & - \\
AIAH-08 & $13 \pm 0.14$ & $14 \pm 0.32$ & $15 \pm 0.38$ & $12 \pm 0.17$ & $16 \pm 0.52$ & $10 \pm 0.27$ & $12 \pm 0.51$ \\
AIAH-09 & - & - & - & - & - & - & - \\
AIAH-10 & $32 \pm 0.23$ & $37 \pm 0.29$ & $30 \pm 0.15$ & $30 \pm 0.53$ & $35 \pm 0.17$ & $28 \pm 0.33$ & $25 \pm 0.27$ \\
AIAH-12 & $06 \pm 0.37$ & - & - & - & $03 \pm 0.19$ & $06 \pm 0.15$ & $02 \pm 0.31$ \\
AIAH-13 & $16 \pm 0.18$ & $11 \pm 0.48$ & $14 \pm 0.19$ & $12 \pm 0.41$ & $02 \pm 0.23$ & $10 \pm 0.29$ & $08 \pm 0.54$ \\
AIAH-14 & - & - & - & - & - & - & - \\
AIAH-15 & $13 \pm 0.14$ & $15 \pm 0.21$ & $10 \pm 0.23$ & $05 \pm 0.17$ & $06 \pm 0.39$ & $04 \pm 0.52$ & $10 \pm 0.41$ \\
AIAH-16 & - & - & - & - & - & - & - \\
AIAH-17 & $05 \pm 0.41$ & $23 \pm 0.14$ & $05 \pm 0.39$ & $07 \pm 0.62$ & $02 \pm 0.69$ & $03 \pm 0.49$ & - \\
AIAH-20 & - & $04 \pm 0.31$ & $06 \pm 0.11$ & $02 \pm 0.21$ & $03 \pm 0.25$ & $06 \pm 0.17$ & $08 \pm 0.29$ \\
AIAH-22 & $15 \pm 0.37$ & $19 \pm 0.33$ & $12 \pm 0.51$ & $11 \pm 0.32$ & $10 \pm 0.14$ & $10 \pm 0.28$ & $12 \pm 0.16$ \\
AIAH-24 & $11 \pm 0.43$ & $02 \pm 0.51$ & $03 \pm 0.37$ & $05 \pm 0.12$ & $06 \pm 0.34$ & $02 \pm 0.44$ & $03 \pm 0.18$ \\
AIAH-25 & $10 \pm 0.16$ & $05 \pm 0.57$ & $05 \pm 0.42$ & $02 \pm 0.26$ & - & $06 \pm 0.31$ & $07 \pm 0.31$ \\
AIAH-26 & $16 \pm 0.25$ & $08 \pm 0.32$ & $05 \pm 0.68$ & $07 \pm 0.43$ & $02 \pm 0.28$ & $03 \pm 0.11$ & - \\
AIAH-27 & - & $02 \pm 0.21$ & $01 \pm 0.29$ & $02 \pm 0.19$ & - & $02 \pm 0.16$ & - \\
AIAH-28 & - & - & - & - & - & - & - \\
AIAH-29 & $28 \pm 0.19$ & $41 \pm 0.42$ & $37 \pm 0.41$ & $30 \pm 0.33$ & $25 \pm 0.43$ & $31 \pm 0.28$ & $27 \pm 0.53$ \\
\hline
\end{tabular}

Legend: The values expressed as mean \pm SEM of $3-4$ experiments. " _ “ indicates no inhibition

Table 3. Growth and Characteristics of strain AIAH-10 on different medium.

\begin{tabular}{lcccc}
\hline Medium & Growth & Aerial mycelium & Reverse mycelium & Pigmentation \\
\hline Trypton -yeast extract agar (ISP-1) & + & Light brown & Light yellow & + \\
Yeast-extract-malt extract agar (ISP- 2) & ++ & $\begin{array}{c}\text { Yellowish } \\
\text { brown }\end{array}$ & Darkish pink & ++ \\
Oatmeal agar (ISP -3) & ++ & Yellowish gray & Dark yellowish orange & ++ \\
$\begin{array}{l}\text { Inorganic salt-starch } \\
\text { agar (ISP- 4) }\end{array}$ & ++ & Grayish yellow & Yellowish white & +++ \\
$\begin{array}{l}\text { Glycerol-asparagine agar (ISP-5) } \\
\text { Tyrosine agar (ISP-7) }\end{array}$ & ++ & $\begin{array}{c}\text { Grayish brown } \\
\text { Light gray }\end{array}$ & Pinkish white & + Dusky yellow \\
Yeast-extract glucose agar (YEGA) & ++ & Yellowish & Dark gray & + \\
\hline
\end{tabular}

Legend, '+++'=High growth, '++'=Moderate growth and '+'=Low growth.

The antifungal activity of the ethyl actate extracts from marine Streptomyces sp. AIAH-10 was determined at a concentration of $50 \mu \mathrm{g} / \mathrm{disc}$ against number of fungi and was found to be 14, 10 and $12 \mathrm{~mm}$ against Aspergillus niger, Saccharromyces cerevaceae 
and Candida albicans respectively (Table 5). It was 18$19 \mathrm{~mm}$ for Nystatin $(30 \mu \mathrm{g} / \mathrm{disc})$ as standard.

The ethyl acetate extracts did not show any hemolytic activity when tested against human erythrocytes. The results of the brine shrimp lethality bioassay are shown in Table 6.Test sample showed different mortality rate at different concentration. The mortality rate of brine shrimp nauplii was found to be increased with the increasing of concentration of the sample. The larval mortality was recorded as $100 \%$ in 40 $\mu \mathrm{g} / \mathrm{ml}$ and higher concentrations. The median lethal concentration $\left(\mathrm{LC}_{50}\right)$ of the extract was found to be 6.61 $\mu \mathrm{g} / \mathrm{ml}$ (Figure 3).

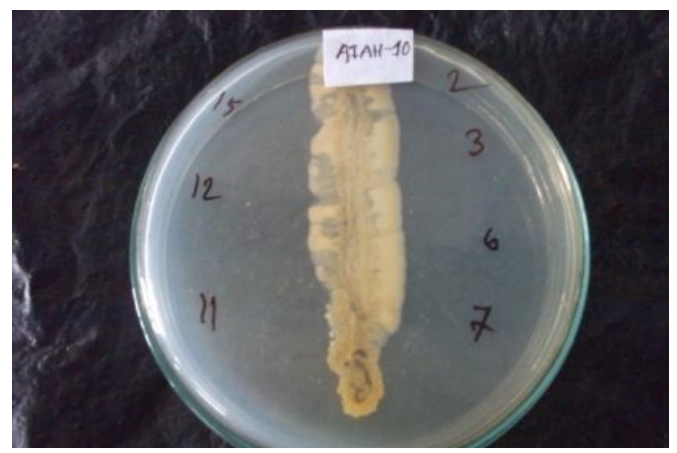

Figure 2. Antibacterial activities of the isolates (against Streptococcus agalactiae (2), Bacillus cereus (3), Pseudomonas aeruginosa (6), Escherichia coli (7), Shigella dysenteriae (11), Shigella sonnei (12) and Agrobacterium (15)) through single line streaking technique.

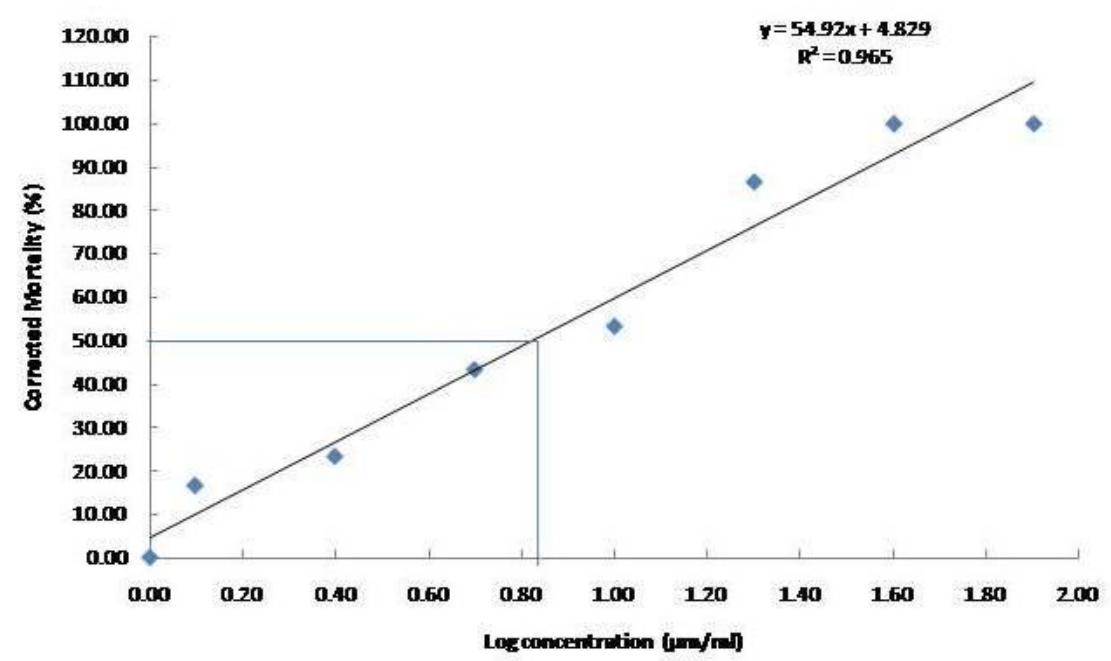

Figure 3. Determination of $\mathrm{LC}_{50}$ by correlating between concentration of the crude extract and percentage of mortality of brine shrimp nauplii.

Table 4. Phenotypic properties of AIAH-10 and a reference strain (Xu et al., 2004).

\begin{tabular}{lcc}
\hline \multicolumn{1}{c}{ Properties } & Results of AIAH-10 & Reference (KM-4927 $)$ \\
\hline Spore chain & Flexuous & Spiral \\
Substrate mycelium color & Grayish yellow & Gray \\
Liquefaction of gelatin & - & - \\
Hydrolysis of starch & + & + \\
Decomposition of cellulose & + & ND \\
Nitrate reduction & + & + \\
NaCl tolerance & $2-4 \%$ & ND \\
Melanoid production & + & ND \\
Sucrose & + & \pm \\
D-Manitol & + & - \\
Inositol & + & + \\
Optimum growth temperature & $32-41^{\circ} \mathrm{C}$ & ND \\
\hline
\end{tabular}


Note, + , positive or utilized; -, negative or not utilized; \pm , ambiguous; ND, not determined.

Table 5. Antifungal activity for the extracts of AIAH-10.

\begin{tabular}{lcc}
\hline Test organisms & \multicolumn{2}{c}{ Zone of inhibition (in mm) } \\
& Nystatin $(30 \mu \mathrm{g} / \mathrm{disc})$ & Extracts $(50 \mu \mathrm{g} / \mathrm{disc})$ \\
\hline Aspergillus niger & $19 \pm 0.52$ & $14 \pm 0.32$ \\
Saccharromyces cerevaceae & $19 \pm 0.57$ & $10 \pm 0.15$ \\
Candida albicans & $18 \pm 0.45$ & $12 \pm 0.24$ \\
\hline
\end{tabular}

Legend, the values expressed as mean \pm SEM of $3-4$ experiments. “ - “ indicates no inhibition.

\section{Discussion}

Actinomycetes are one of the major groups of organisms present in both terrestrial and marine environment (Imada et al., 2005). In the present study, actinomycetes were isolated from the soils samples of mangrove forest Sundarban, Bangladesh using isolation media. The isolation media contains starch and casein as sole carbon and energy sources. Only organisms capable of degrading these complex polymers (mostly molds and Streptomyces) are able to grow (Sharmin et al., 2013). Among 29 isolated strains (AIAH-1 to AIAH-29), the strain AIAH-10 was selected for further study due to its potent antibacterial property against a series of pathogenic bacterial strains. On the basis of cultural, morphological and biochemical properties, AIAH-10 was characterized as Streptomyces sp. Similar procedure was followed for the identification of Streptomyces in "International Streptomyces Project" (Nonomura, 1974). Previous works on novel antibiotics reported that a high proportion of organisms possessing antimicrobial activity belong to the genus Streptomyces (Demain et al., 2009 and Ceylan et al., 2008).

The crude extracts exhibited significant antifungal activity against the pathogenic fungi where as previous study (Abdul Alim et al., 2006) reported that actinomycetes sp. exhibited 12,10 and $10 \mathrm{~mm}$ of zone of inhibition to Aspergillus niger, Saccharromyces cerevaceae and Candida albicans respectively that was less to compared our findings. The extracts did not show hemolytic activity to the human erythrocytes therefore it could be considered as safe for human use. In brine shrimp lethality bioassay, it was found that the extracts exhibited dose dependent activity and medial lethal concentration $\left(\mathrm{LC}_{50}\right)$ was found to be 6.661 $\mu \mathrm{g} / \mathrm{ml}$. In earlier studies (Ruhul et al., 2003), the reported value was $17.78 \mu \mathrm{g} / \mathrm{ml}$. Compare to other studies, our isolated Streptomyces sp. exhibited more antifungal and cytotoxic activity.

Conclusion

Therefore it can be concluded that the marine Streptomyces sp. AIAH-10 may be an interesting source for obtaining molecules. However further study is required to determine the structure of responsible compound and to identify the strain to its species level sequencing of $16 \mathrm{~S}$ rDNA.

\section{Acknowledgements}

We are grateful to ministry of National Science and Technology (NST), Government of Bangladesh, for founding us to carrying out this work. We are also grateful to "International Centre for Diarrhoeal Disease Research' Bangladesh” (ICDDR'B) for providing pathogenic fungi. These contributions are greatly acknowledged.

\section{References}

Abdul Alim, A.B., Khan, A., Sayeed, M.A., Sazedur, M.R. and Mossadik, M.A. 2006. Characterization and antimicrobial activities of phthalic acid derivative produced by Streptomyces bangladeshiensis a novel species collected in Bangladesh. Res. J. Med. Medic. Sci. 1, 77-81.

Berdy, J. 1995. Are Actinomycetes exhausted as a source of secondary metabolites? Proceedings of the 9th Symposium Actinomycetes. pp. 13-34.

Carte, B.K. 1996. Biomedical potential of marine natural products. Bioscience 46, 271-286. 
Ceylan, O., Okmen, G. and Ugar, A. 2008. Isolation of soil Streptomyces as source of antibiotics active against antibiotic-resistant bacteria. Eur. Asia. J. Biosci. 2, 7382.

Demain, A.L. and Sanchez, S. 2009. Microbial drug discovery: 80 years of progress. J. Antibiotics 62, 5-16.

Haque, M.A., Sarker, A.K., Islam, M.S. and Islam, M.A. 2015. Antibacterial Potential of Ethyl-Acetate Extracts of Marine Streptomyces sp. AIAH-10 against Drug Resistant Escherichia coli. British Microbiol. Res. J. 6, 143-150.

Haque, M.A., Sarker, A.K., Islam, M.S., Rahman, M.A., Chouduri, M.A.U. and Islam, M.A. 2014. In vitro Insecticidal and Time-Kill Profile of Ethyl Acetate Extract of Marine Streptomyces sp. Isolated from Sundarbans, Bangladesh. Bangladesh Pharm. J. 17, 151156.

Imada, C., Koseki, N., Kamata, M., Kobayashi, T. and Hamada-Sato, N. 2005. Isolation and characterization of antibacterial substances produced by marine actinomycetes in the presence of seawater. Actinomycetologica 21, 27-31.

Iqbal, M., Ali, K.M., Daraz B. and Siddique, U. 2004. Bacteriology of mastitic milk and in vitro antibiogram of the isolates. Pak. Vet. J. 24, 161-164.

Jaki, B.N., Orajala, J., Burji, H.R. and Sticher, O. 1999. Biological screening of cyanobacteria for antimicrobial and molluscicidal activity, brine shrimp lethality and cytotoxicity. J. Pharm. Biol. 37, 138-143.

Jensen, P.R., Gontang, E., Mafnas, C., Mincer, T.J. and Fenical, W. 2005. Culturable marine Actinomycetes diversity from tropical Pacific Ocean sediments. Appl. Environ. Microbiol. 7, 1039-1048.

Karthik, L., Gaurav, K. and Bhasakara, K.V. 2010. Diversity of marine Actinomycetes from Nicobar marine sediments and its anti fungal activity. Int. J. Pharm. Phar. Sci. 2, 199-203.

Mayer, B.N., Ferrigni, N.R., Putnam, J.E., Jacobsen, L.B., Nichols, D.E. and Mclaughlin J.L. 1982. Brine shrimp: a convenient bioassay for active plant constituents. Plant Medica. 45, 31-34.

Nonomura, H. 1974. Key for classification and identification of 458 species of the Streptomycetes included in ISP. $J$. Fermen. Technol. 52, 78-92.

Rahman, M.A., Islam, M.Z., Khondkar, P. and Islam, M.A. 2010. Characterization and antimicrobial activities of a polypeptide antibiotic isolated from a new strain of Streptomyces parvulus. Bangladesh Pharm. J. 13, 14-16.
Ruhul, R.M., Jabbar A. and Rashid, M.A. 2003. Antimicrobial and cytotoxic activities of metabolites isolated from a Penicillium strain. Pak. J. Biol. Sci. 6, 1365-1367.

Santina, M., Luigi, M., Consolazione, Matteo, B., Vivia, B., Renato, F. and Angelina, L.G. 2009. Antagonistic interaction between psychrotrophic cultivable bacteria isolated from Antartic sponges: A priliminary analysis. Res. Microbiol. 160, 27-37.

Sarker, A.K., Haque, M.A., Islam, M.S., Rahman, M.A. and Islam, M.A. 2015. Isolation and Characterization of a Marine Bacterium from Sundarbans, Bangladesh. British Microbiol. Res. J. 6, 348-357.

Sathish, S.R., Charles, L.P. and Kokati, B.R. 2011. Phytochemical composition, antimicrobial and hemolytic activity of Solanum trilobatum Linn. Pharmacologyonline 3, 1336-1341.

Schwartsmann, G., Brondani, A.R,. Berlinck, R.G.S. and Jimeno, J. 2001. Marine organisms as a source of new anticancer agents. Lancet Oncol. 2, 221-225.

Semedo, L.T.A.S., Linhares, A.A., Gomes, R.C., Manfio, G.P., Alviano, C.S., Linhares L.F. and Coelho, R.R.R. 2001. Isolation and characterization of actinomycetes from Brazilian tropical soils. Microbiol. Res. 155, 291298.

Sharmin, T., Rahman, M.A., Anisuzzaman, A.S.M. and Islam, M.A. 2013. Antimicrobial and cytotoxic activities of secondary metabolites obtained from a novel species of Streptomyces. Bangladesh Pharm. J. 16, 15-19.

Siva, K., Maloy, K.S. and Kathiresan, K. 2005. Isolation and characterization of Streptomycetes producing antibiotic from mangrove environment. Asian J. Microbiol. Biotech. Environ. Sci. 7, 457-464.

Siva, K. 2001. Actinomycetes of an Indian Mangrove (Pichavaram) environment. Indian J. Mar. Sci. 28, 6775.

Watve, M.G., Tickoo, R., Jog, M.M. and Bhol, B.D. 2001. How many antibiotics are produced by the genus Streptomyces? Archives Microbiol. 176, 386-390.

Xu, P., Yo ko, T., Akio., Yuzuru, I. and Satoshi, O. 2004. Streptomyces scabrisporus sp. nov. Int. J. Syst. Evo. Microbiol. 54, 577-581.

Uzzal, M., Rahman, M.A., Haque, M.A., Sarker, A.K. and Islam, M.A. 2015. Modulation of antibacterial activity of actinomycetes by co-culturewith pathogenic bacteria. Bangladesh Pharm. J. 18, 61-65. 